\title{
Computer Software for Determine Atmospheric Stability for Air Pollution Modeling
}

\author{
Emad A. Ahmed
}

\begin{abstract}
Atmospheric stability plays the most important role in the transport and dispersion of air pollutants. So that it's the important input in air dispersion pollution modeling. In this study develop computer software to determine atmospheric stability class. This software is adopted completely Graphical User Interface (GUI) technique and its interface has been designed by Microsoft Visual studio 2015. Development of the software depends on the Pasquill-Turner classification. The software applied on Qena as a case study for five years. Results output from the software compared to manual calculations and proved it $100 \%$ compatible. Therefore we can use this software to determine the atmospheric stability class at any climate condition.
\end{abstract}

Keywords - Atmospheric stability, Pasquill-Turner classification, Air pollution modeling, Computer software, computation physics.

\section{Introduction}

The transport and dispersion of air pollutants depend mainly on the atmospheric stability. It can be defined as the atmospheric tendency to reduce or intensify vertical motion or alternatively, to suppress or augment existing turbulence $[1,2]$. To know and estimate the ability of atmosphere to disperse pollutants must be determine the degree of stability of the atmosphere [3]. Three main stability conditions in the atmospheric boundary layer can be observed: neutral, stable and unstable conditions. These stability conditions can be explained by an example of a moving air particle [4]

There are different methods used to determine atmospheric stability with varying degrees of complexity [5]. Most of these methods are based on the relative importance of convective and mechanical turbulence in atmospheric motions. Difference between such methods is due to use of different indicators for both convective and mechanical turbulence. Generally, when convective turbulence predominates, winds are weak and atmosphere is in unstable condition. When convection decreases and mechanical turbulence increases, atmosphere tends to neutral conditions. Finally in absence of convective turbulence when mechanical turbulence is dampened and there is no vertical mixing, atmosphere is in stable condition $[6,7]$.

This study provides computer software to help researchers to determine the atmospheric stability. This software is adopted completely Graphical User Interface (GUI) technique to easy use. Also, the software applied on Qena (Upper Egypt) as a case study for five years. The results output from the software are analyzed.

Emad Ali Ahmed

Faculty of sciences / South Valley University

Egypt

Emad.Amer@sci.svu.edu.eg

\section{Theory and the software}

Atmospheric stability is categorized into six states, A - F, ranging from Extremely Unstable to Moderately Stable [8, 9], as shown in Table (1). The stability is influenced by wind speed, solar radiation and the resultant heating of the ground. Stability classes can be estimated from the wellknown Pasquill look-up table in Table (2) [10, 11].

TABLE 1: Definitions of atmospheric stability states.

\begin{tabular}{|c|c|c|}
\hline Class & Designation & Example conditions \\
\hline A & Extremely Unstable & Low wind speed, clear bright day \\
\hline $\mathrm{B}$ & Moderately Unstable & Low wind speed, some cloud cover \\
\hline $\mathrm{C}$ & Slightly Unstable & $\begin{array}{l}\text { Moderate wind speed, some cloud } \\
\text { cover }\end{array}$ \\
\hline $\mathrm{D}$ & Neutral & $\begin{array}{l}\text { Moderate to strong wind, cloud cover } \\
\text { or night }\end{array}$ \\
\hline & & Low wind speed, cloudy night \\
\hline $\mathrm{E}$ & Slightly Stable & Low wind speed, clear night \\
\hline $\mathrm{F}$ & Moderately Stable & \\
\hline
\end{tabular}

According to table (2), Pasquill-Gifford method for estimating atmospheric stability, incorporating considerations of both mechanical and buoyant turbulence was proposed by Pasquill (1961) [10]. It is a simple method because it is easy to use and tends to give satisfactory results [13]. In this classification, it is assumed that stability in the layers near the ground depends on net radiation as an indication of convective turbulence and on wind speed at 10 $\mathrm{m}$ height as an indication of mechanical turbulence. Net radiation could be determined based on insolation (incoming solar radiation) and cloud cover at day or night time separately. The primary advantages of this classification are its simplicity and its requirement of only routinely available information from surface meteorological stations, such as the near-surface $(10 \mathrm{~m})$ wind speed, solar radiation and cloudiness [14].

In this study, an attempt was made to introduce computer software to determination of atmospheric stability conditions. The development of software is based upon the work of Pasquill-Gifford method. The importance of this method lies in the relation of atmospheric dispersion coefficients and classified stability for mechanically and thermally generated boundary-layer turbulence [13]. Therefore, the output of this software is useful to the air pollutants dispersion models.

The software is adopted completely Graphical User Interface (GUI) technique for operating in various windowsbased microcomputers. The software interface has been designed using by Microsoft Visual studio 2015. It is based on the flow chart as in Fig. (1) 
TABLE 2: Atmospheric stability classification Of Pasquill [12].

\begin{tabular}{|c|c|c|c|c|c|}
\hline \multirow{2}{*}{$\begin{array}{l}\text { Surface } \\
\text { wind Speed } \\
\text { @ } 10 \mathrm{~m} \\
\text { elevation } \\
(\mathrm{m} / \mathrm{s})\end{array}$} & \multicolumn{3}{|c|}{$\begin{array}{c}\text { Day } \\
\text { solar insolation }\end{array}$} & \multicolumn{2}{|c|}{$\begin{array}{l}\text { Night } \\
\text { Cloudiness }\end{array}$} \\
\hline & Strong & Moderate & Slight & $\begin{array}{l}\text { Cloudy } \\
(\exists 4 / 8)\end{array}$ & $\begin{array}{c}\text { Clear } \\
(<4 / 8)\end{array}$ \\
\hline$<2$ & $\mathbf{A}$ & A-B & B & $\mathbf{E}$ & $\mathbf{F}$ \\
\hline $2-3$ & A-B & B & C & $\mathbf{E}$ & $\mathbf{F}$ \\
\hline $3-5$ & B & B-C & C & D & $\mathbf{E}$ \\
\hline $5-6$ & $\mathrm{C}$ & C-D & $\mathbf{D}$ & $\mathbf{D}$ & $\mathbf{D}$ \\
\hline$>6$ & $\mathrm{C}$ & D & D & D & D \\
\hline
\end{tabular}

\section{Estimating Degree of Insolation:}

Strong: Clear summer day: sun elev. $>60$ deg.; solar radiation $>143 \mathrm{cal} / \mathrm{m}^{2} / \mathrm{sec}$.

Moderate: Summer day: few broken clouds or clear, sun elev. 35 to $60 \mathrm{deg}$.; solar radiation: 72 to $143 \mathrm{cal} / \mathrm{m}^{2} / \mathrm{sec}$.

Slight: Fall afternoon, cloudy summer day, or clear summer day: sun elev. 15 to $35 \mathrm{deg}$.; solar radiation $<72 \mathrm{cal} / \mathrm{m}^{2} / \mathrm{sec}$.

By using this software determine the hourly atmospheric stability at day or night time. In this case user input wind speed, solar radiation and cloud amount in the allotted text box. In additions to that, the software can use to the daily, monthly and yearly atmospheric stability, respectively by select the convenient input file with MS excel format and the output result export in the same file. Fig. (2) show the GUI main form of the software. As shown in this figure the form is divided into four parts to determine the atmospheric stability class at hourly, daily, monthly and yearly, respectively.

\section{Results and discussions}

As a case study, the software applied at Qena (Upper Egypt) to determine the atmospheric stability for five years (2011-2015). The data used as input in the software was collected at the South Valley University-Meteorological Research Station, located at Qena, which is one of the guide stations of the Egyptian Meteorological Authority.

The software takes into determine the hourly atmospheric stability class about 2 seconds. Therefore, to determine the daily repeat the hourly process 24 times. in determine the monthly and yearly atmospheric stability class repeat that 720 and 8640 time, respectively.

The output results from the software were analyzed statistically. Fig. (3) show the statistically analysis for the atmospheric stability class at Qena from 2011 to 2015. As shown in the figure the stability class $\mathrm{D}$ has the higher frequency percentage about $26 \%$ while the class C-D has the lower frequency percentage about $1 \%$.
Statistical analysis for the three major state of the atmospheric stability (unstable, neutral and stable), as shown in Fig. (4). From this figure the unstable state of the atmospheric at Qena has the higher frequency percentage about $46 \%$. This value is consistent with the climatic condition of the city where it's lies within the subtropical region and its terrain is semi-desert. The climate of Qena is characterized by a hot season from March to September and a cold season from October to February [15].

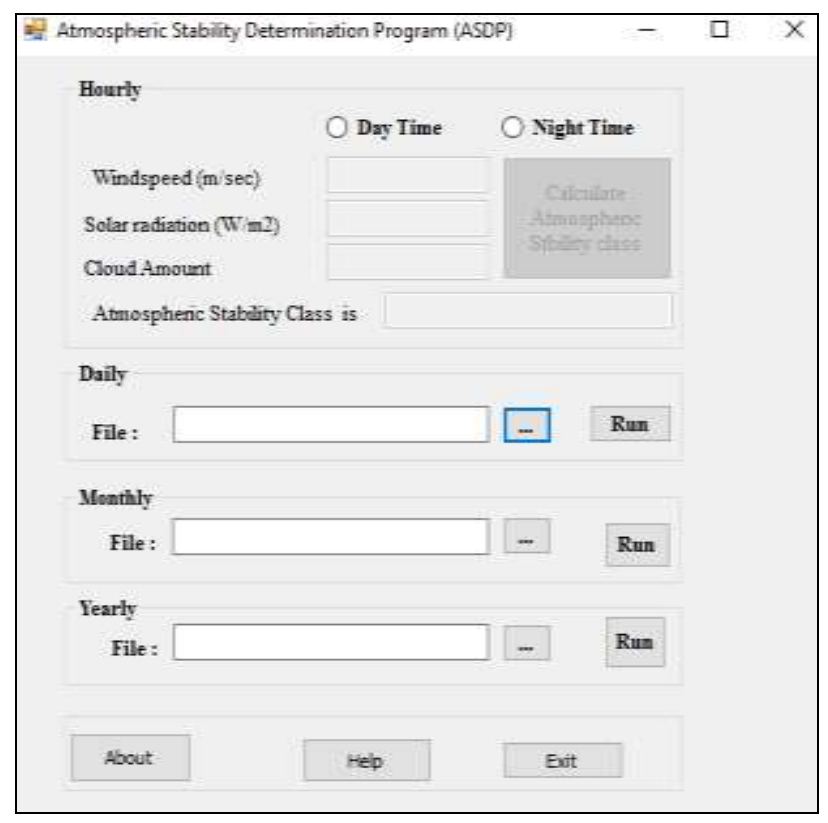

Figure 2: Main form of the software 
Proc. of the International Conference on Advances in Bio-Informatics and Environmental Engineering - ICABEE 2016. Copyright (C) Institute of Research Engineers and Doctors. All rights reserved.

ISBN: 978-1-63248-100-9 doi: 10.15224/ 978-1-63248-100-9-80

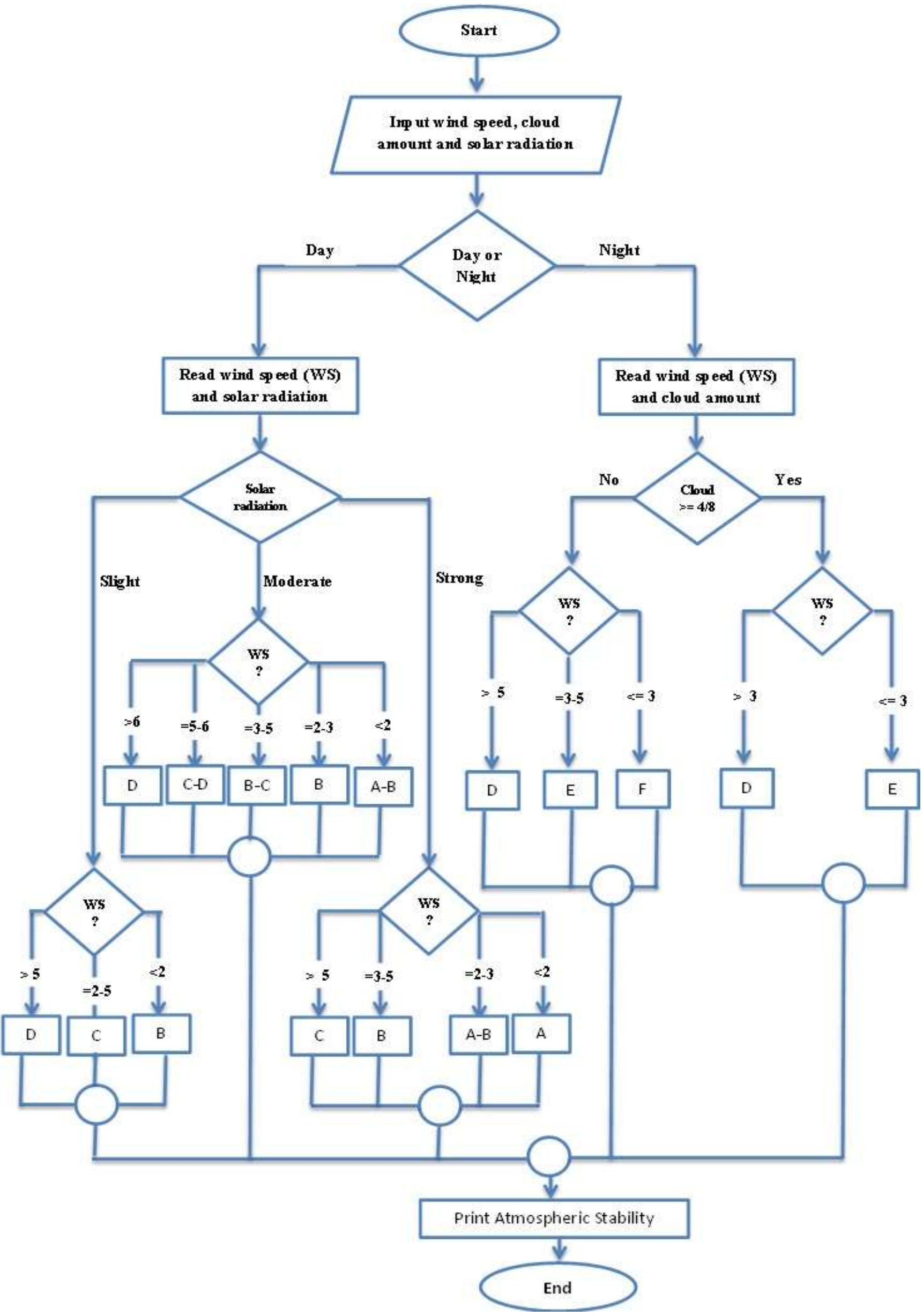

Figure 1: Flow chart of the software 


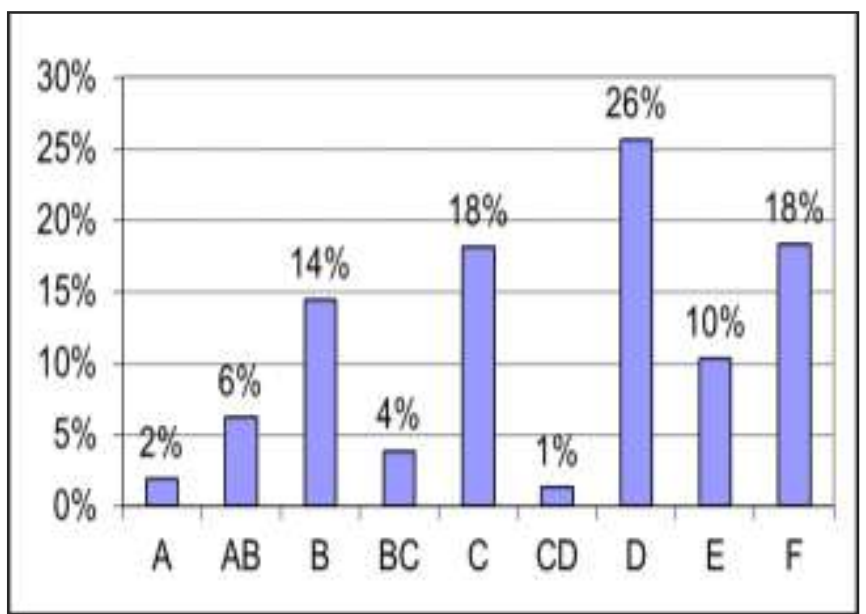

Figure 3: Frequency percentage of the atmospheric stability classes for Qena 2011-2015.

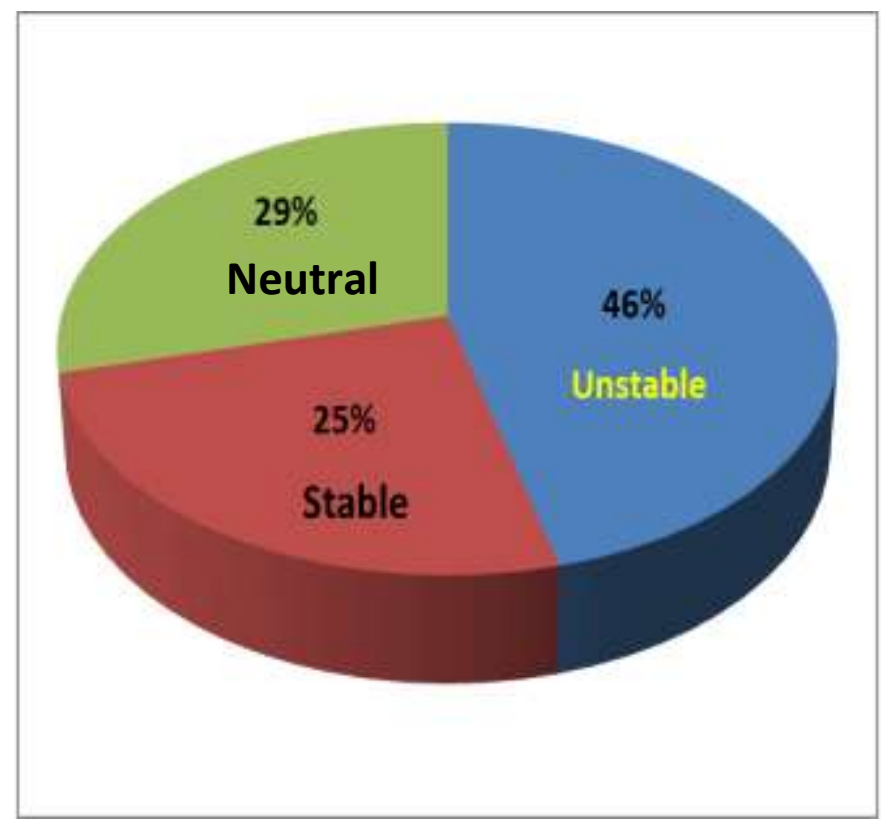

Figure 4: Frequency percentage of the atmospheric stability State (unstable, neutral and stable) for Qena 2011-2015.

\section{CONCLUSIONS}

The present study is an attempt to development of computer software to determine atmospheric stability class. This software is adopted completely Graphical User Interface (GUI) technique and its interface has been designed by Microsoft Visual studio 2015 with relate MS Excel. Development of the software depends on the Pasquill-Turner classification.

We have been used the software to determine atmospheric stability class at Qena (Upper Egypt) for five years from 2011 to 2015. Overall the output results from the software agree quite satisfactorily with manual determination. Therefore, this software is very suitable to determination atmospheric stability class.

\section{Acknowledgments}

The author would like to thank the atmospheric environmental laboratory member at physics department, faculty of science south valley university, Egypt for their supporting and helping to apply this software.

\section{References}

[1] Zoras, S., Triantafyllou, A.G, Deligiorgi, D., "Atmospheric stability and PM10 concentrations at far distance from elevated point sources in complex terrain: Worst-case episode study". J. of Environmental Management, 80, pp. 295-302, 2006.

[2] Kh. Ashrafi, and Gh. A. Hoshyaripour, "A Model to Determine Atmospheric Stability and its Correlation with CO Concentration", International Journal of Environmental, Chemical, Ecological, Geological and Geophysical Engineering Vol:2, No:8, 2008

[3] Wark, K., Warner, C.F., Davis, W.T., "Air pollution: Its Origin and Control”. Addison-Wesley, 1998.

[4] J.J.W. Hutschemaekers, "Comparison of classification systems to define Atmospheric Stability and their impact on Wind Turbine Design", Master of Science in Sustainable Energy Technology at Delft University of Technology, September 8, 2014

[5] Muhan M., Siddiqui T.A., "Analysis of various schemes for the estimation of atmospheric stability classification". Atmospheric Environment, Vol. 32, pp: 3775-3781, 1998.

[6] Schenelle, K.B, Dey, P.R., "Atmospheric dispersion modeling compliance guide". McGrawHill companies, 2000.

[7] Ahmed F. Hassoon, Samar K. Mohammed, Hazim H. Hussain Al-Saleem, "Atmospheric Stability and Its Effect on the Polluted Columns of Concentrations in North West of Baghdad City", Iraqi Journal of Science, 2014, Vol 55, No.2A, pp: 572-581.

[8] Masters, G. M., "Introduction to Environmental Engineering and Science", $2^{\text {nd }}$ Prentice Hall, 1991.

[9] Emad A. Ahmed, "Air pollution modeling in urban environment", PhD Thesis, Faculty of science, South Valley University, 2010.

[10] Pasquill, F.: "The estimation of the dispersion of windborne material", The Meteorological Magazine, vol 90, No. 1063, pp 33-49, 1961.

[11] Pasquill, F., "Atmospheric Diffusion", 2nd Edition. Ellis Horwood Limited, Chichester. ISBN 085312015 3. 1974.

[12] Ronald T. Borochoff, "Model for Mercury Deposition from smoke Plumes", Intelligence in Materials World, P. 615-628, CRC Press Raton, USA. 2003. 
Proc. of the International Conference on Advances in Bio-Informatics and Environmental Engineering - ICABEE 2016. Copyright (c) Institute of Research Engineers and Doctors. All rights reserved.

ISBN: 978-1-63248-100-9 doi: 10.15224/ 978-1-63248-100-9-80

[13] Zoras, S., Triantafyllou, A.G, Deligiorgi, D., "Atmospheric stability and PM10 concentrations at far distance from elevated point sources in complex terrain: Worst-case episode study". J. of Environmental Management, 80, pp. 295-302, 2006

[14] Ludwig, F.L., "Comparison of two practical atmospheric stability classification schemes in an urban application", J. Appl. Meteor., 15, pp. 1172-1176, 1976.

[15] S. M. Robaa, "On the estimation of UV - B radiation over Egypt", IDOJARAS, Quarterly Journal of the Hungarian Meteorological Service, 112, 45 - 60, 2008.

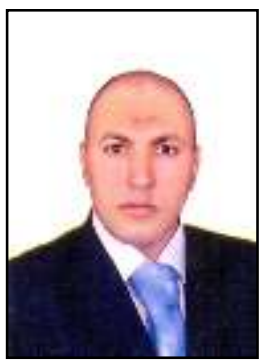

Emad Ali Ahmed was born in Luxor, Egypt, on August 14, 1978. $\mathrm{He}$ received his BSc., MSc. and $\mathrm{PhD}$. in physics from South Valley University, faculty of science, Qena, Egypt in 1999, 2005 and 2010, respectively. He is currently with physics department, faculty of sciences, South Valley University, Qena, Egypt. His research interests are Atmospheric Physics, Computation of physics, Theoretical \& Applied physics and Application of Computer in Physics. 